Ann. Zootech., 1980, 29, no h. s., 27-47.

\title{
Expected growth rates according to energy systems for cattle (*)
}

\author{
H. REFSGAARD ANDFRSEN and J. FOLDAGER \\ National Institute of Animal Science \\ 25 Rolighedsvej, DK-1958 Copenhagen V (Denmark)
}

\begin{abstract}
Representatives from 16 COST countries were asked to estimate daily gains in bulls, steers and heifers fed five different rations at 200 ans $400 \mathrm{~kg}$ respectively. The $5 \times 2$ rations were formulated from six different feeds of known chemical composition and digestibilities.

The expected daily gains vary from country to country, and differences between countries are especially large at low levels of feeding. The differences are due to differences in breeds, the relative energy value of the feeds, and differences in the energy recommendations. Furthermore, the expected differences in gain between the sexes are highly variable.

A relative feed conversion ratio was estimated at various levels of feeding. In most countries it is expected that the feed conversion ratio (energy intake/ $\mathrm{kg}$ gain) increases at decreasing levels of feeding in bulls, steers and heifers. Furthemore, the feed conversion ratio at increasing liveweights also shows some variation.
\end{abstract}

\section{Résumé}

\section{Prévision de la vitesse de croissance selon les différents systèmes énergétiques utilisés pour les bovins}

\section{(Résumés du questionnaire envoyé aux différents pays)}

On a demandé à des représentants des 16 pays de la Communauté Européenne élargie de prédire, à partir des systèmes d'évaluation des besoins et apports énergétiques en vigueur dans leurs pays respectifs, les gains journaliers de taurillons, bœufs et génisses recevant 5 rations différentes, au poids de $200 \mathrm{~kg}$ et au poids de $400 \mathrm{~kg}$. Les $5 \times 2$ rations étaient composées à partir de 6 aliments dont la composition chimique et la digestibilité étaient données au préalable. Les gains de poids journaliers prévus, pour une même ration et un même type d'animal, varient selon les pays; les différences sont particulièrement importantes pour des niveaux alimentaires faibles. Ces variations résultent de différences entre les races de bovins considérées, entre les valeurs énergétiques relatives des aliments, et entre les apports énergétiques recommandés. De pius, les différences liées au sexe dans les gains de poids prévus sont très variables. Le coût énergétique du $\mathrm{kg}$ de gain (énergie consommée par $\mathrm{kg}$ de gain) a été calculé à différents niveaux d'alimentation. Dans la plupart des pays on considère toujours que le coût énergétique du $\mathrm{kg}$ de gain augmente à mesure que diminue le niveau d'alimentation des taureaux, bœufs et génisses. En outre, l'augmentation du coût énergétique $\mathrm{du} \mathrm{kg}$ de gain avec le poids vif varie aussi selon les pays.

\footnotetext{
* (Summary of results from questionnaires circulated to COST countries.)
} 


\section{Introduction}

An economic evaluation of a feed ration to a group of growing animals can only be performed if it is possible to predict the production on alternative rations. For this purpose the necessary prerequisites are : expected feed intake, energy value of the feeds, and the animals requirement for energy.

Evaluation of the energy content in feeds varies between countries due to differences in the energy systems used. Furthermore, the energy standards used can vary. The purpose of this paper was to compare the energy systems used in the COST countries.

\section{Materials}

Prior to this meeting questionnaires were circulated to representatives from Belgium (B), Denmark (DK), West Germany (D), Finland (SF), France (F), Greece (GR), Ireland (IRL), Italy (I), Luxembourg (L), the Netherlands (NL), Portugal (P), Sweden (S), Switzerland (CH), Turkey (TR), United Kingdom (GB), and Yugoslavia (YU). All countries, except Portugal and Turkey, have answered the questionnaires.

The representatives were asked to calculate the energy content of six different feeds with known chemical compositions and digestibilities (Table 1). Furthermore, they were asked to calculate the total energy content in 5 rations for animals of 200 and $400 \mathrm{~kg}$ liveweight respectively (Table 2), and the expected daily gains if bulls, steers and heifers were fed these rations (Table 3 ). The main components in the rations were :

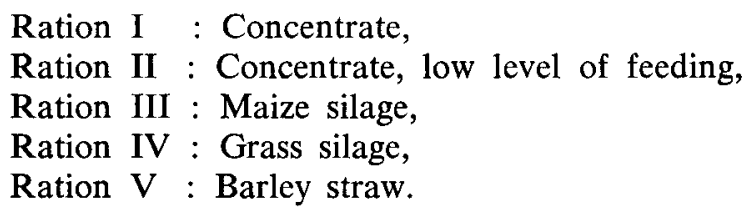

Due to differences in the energy requirements of various breeds, the representatives were asked to make reference to the breed in question and, if applicable, to make estimates for early, medium and late maturing breeds.

\section{Results}

\section{Energy systems}

In the COST countries a number of different energy systems are used. United Kingdom, Ireland and Sweden use metabolisable energy, whereas the remaining countries use different net energy systems (Tables 4). Both France and the Netherlands have two feed units, one for maintenance + growth, and one for lactation. In France the feed unit for lactation (UFL) is used for all categories of animals when the rate of growth is less than $750 \mathrm{~g} / \mathrm{day}$. In the Netherlands the feed unit for lactation (VEM) is used for growth in replacement heifers. 


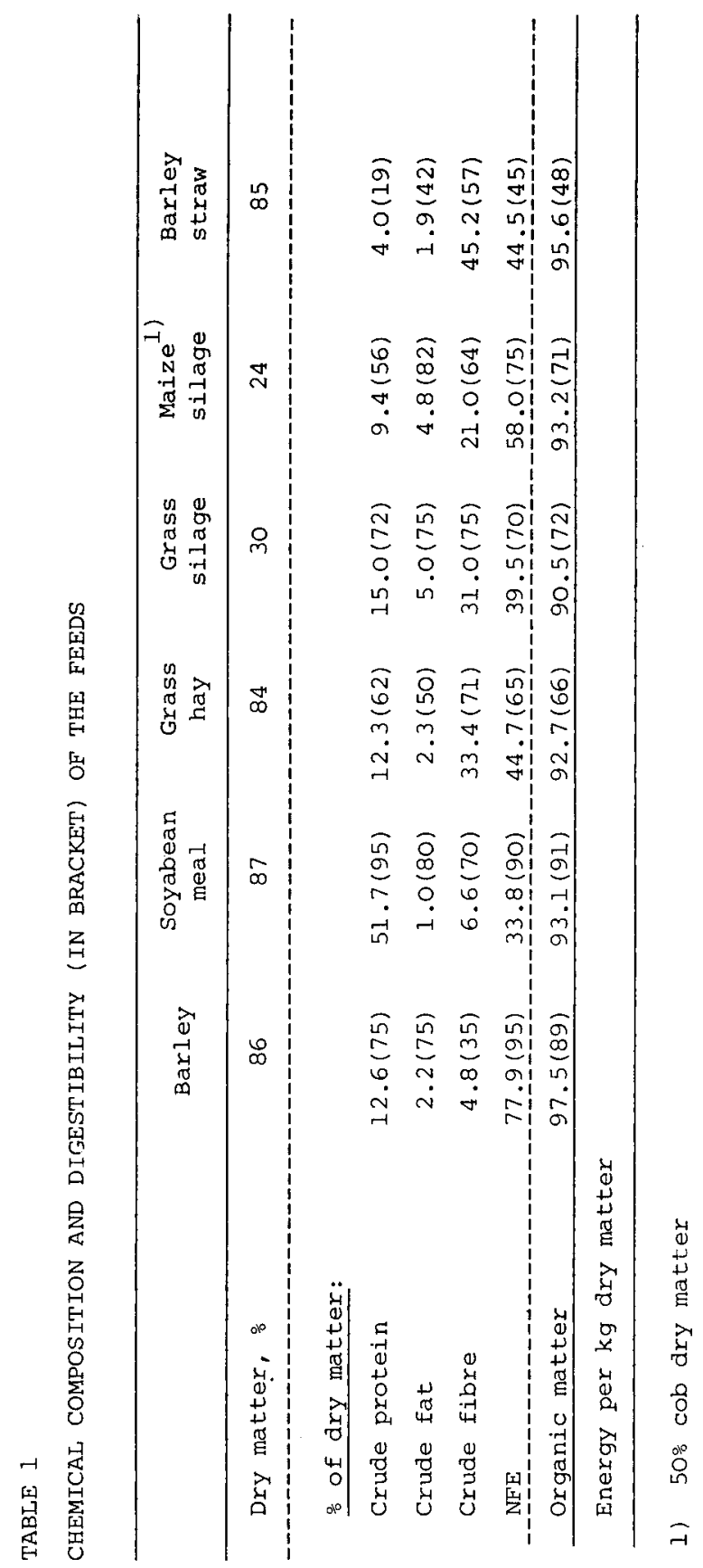




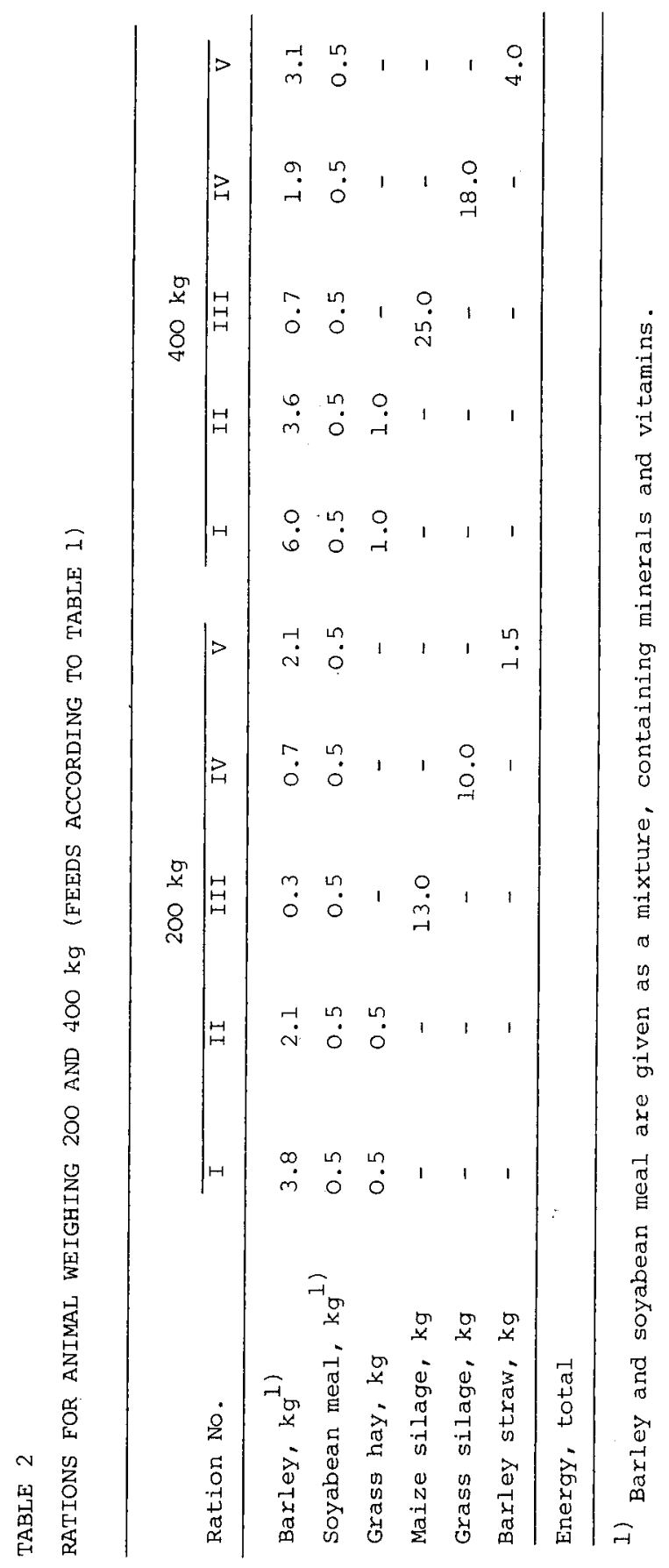


EXPECTED GROWTH ACCORDING TO ENERGY SYSTEMS

㖟

㴶

赑

舆

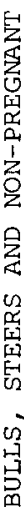

忩

s)

窇

葟

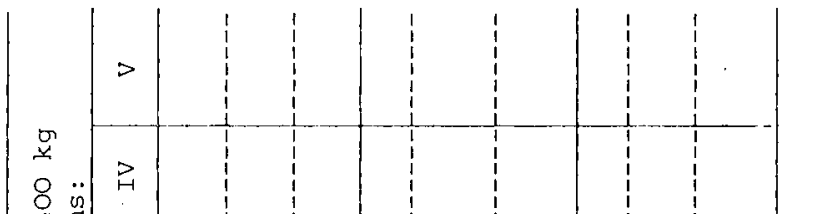

竓

$\frac{9}{4}$

넝

몽

苦

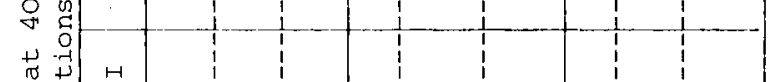

药

द

o.

걱면

年

$-$
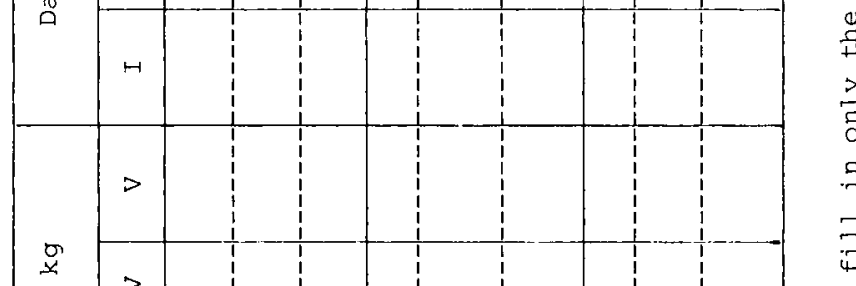

…

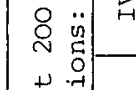

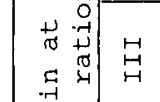

$\mid \begin{array}{cc}0 \\ 0 \\ 0 \\ 0 \\ 0 \\ 7\end{array}$

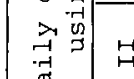

몸

8

是

유

崫

$z$

붕그

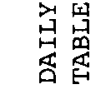

m 品否

罢器尊

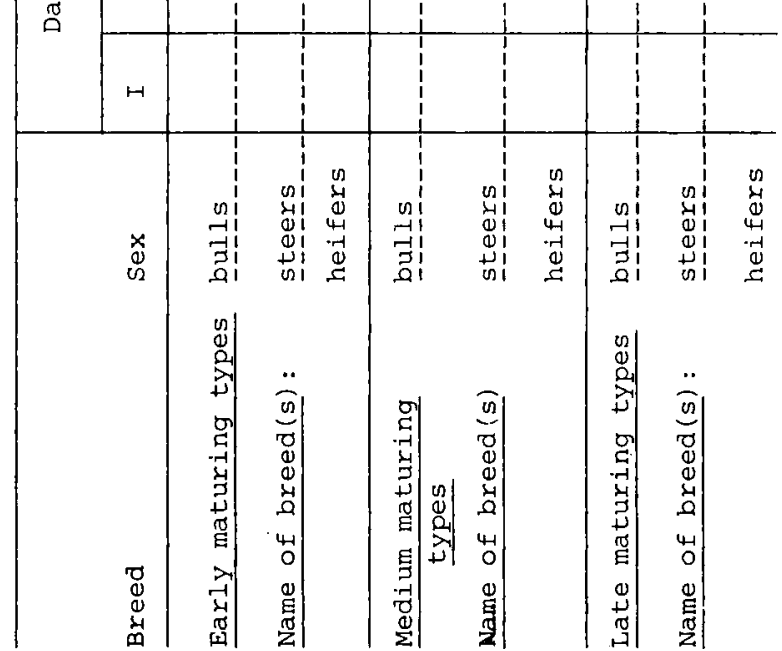

임

$\exists$

空

.

-

ס্

㟧

T

嘀

量

量

푼

号

วิ

$H$ 


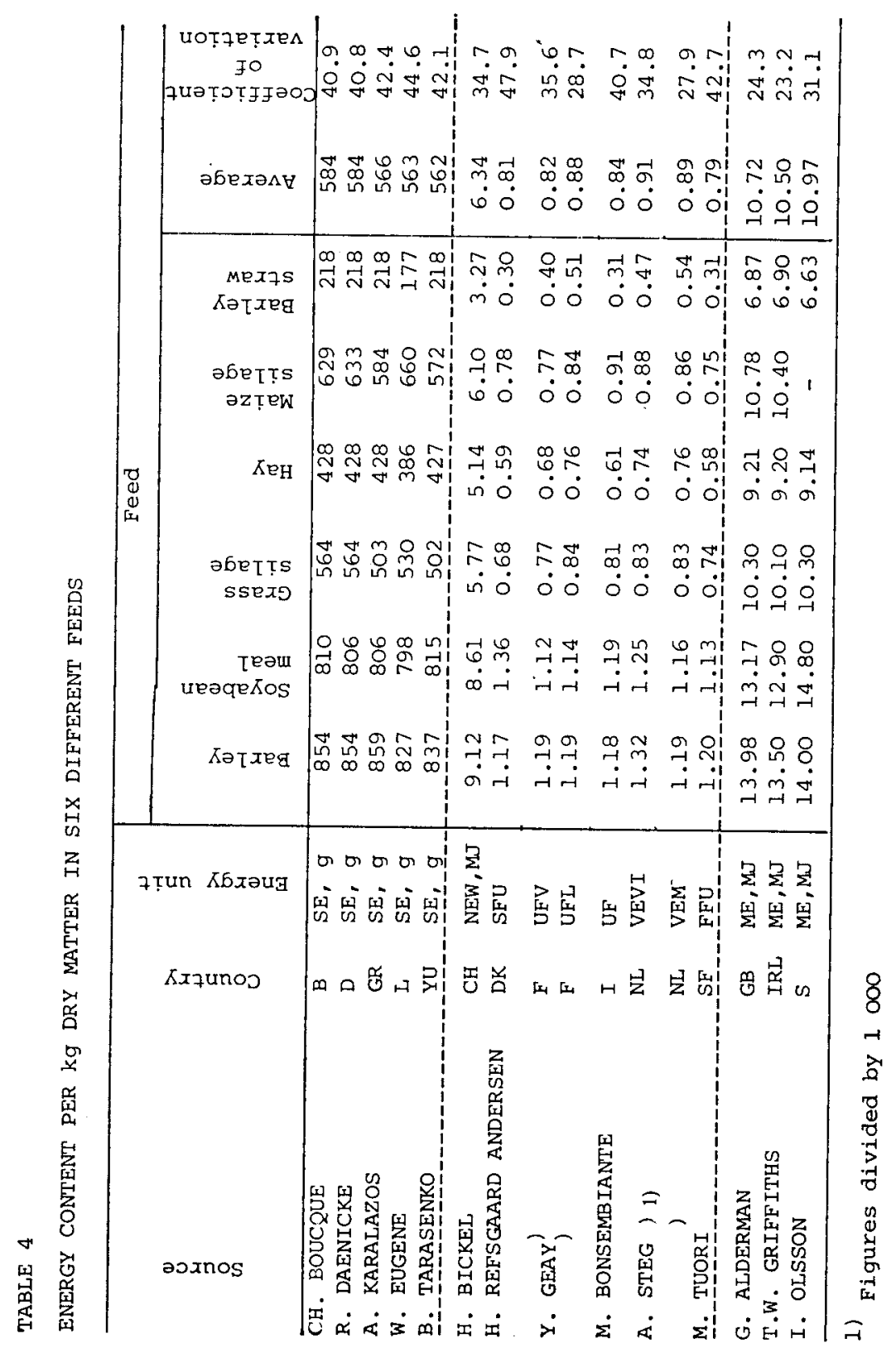




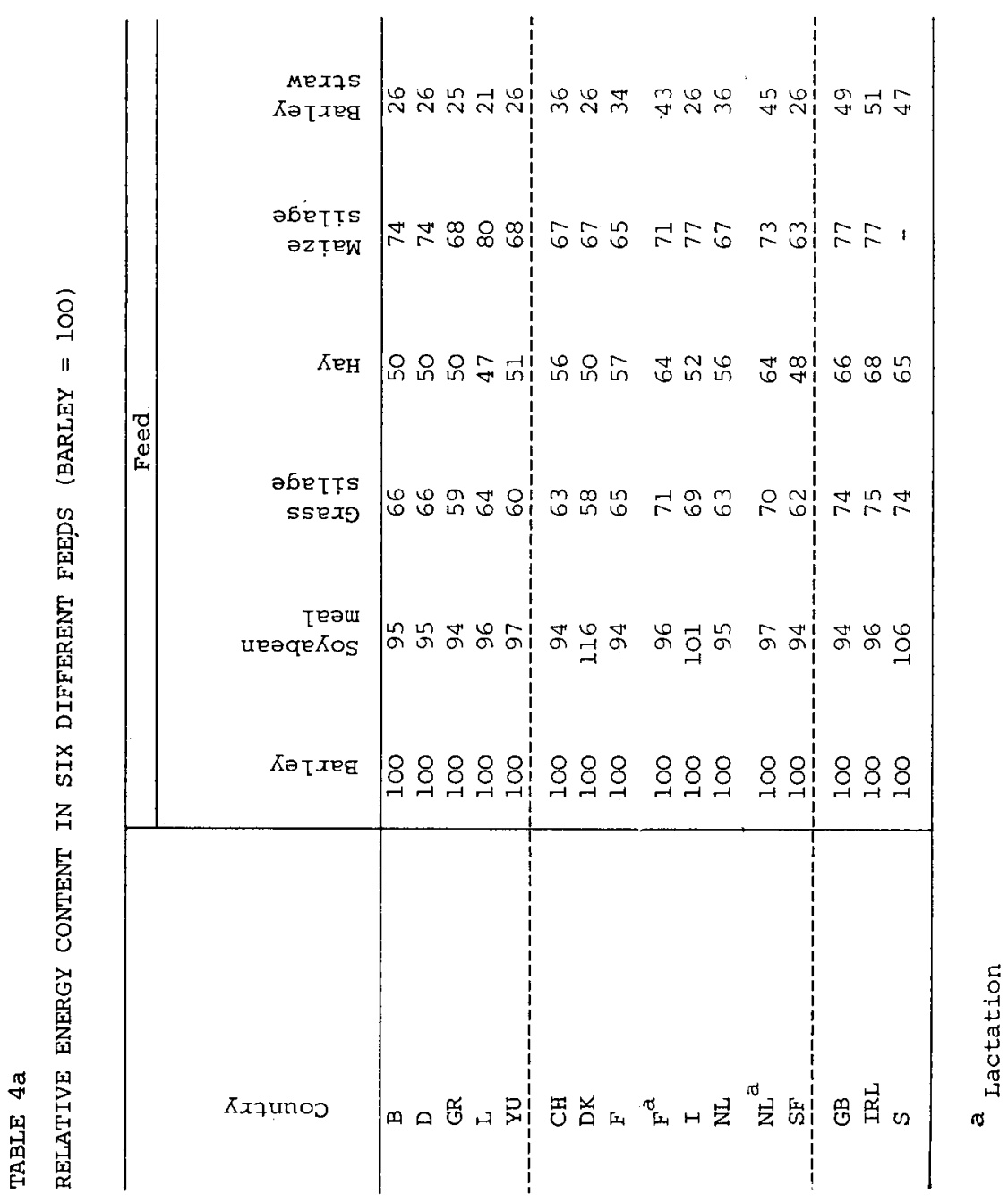


Generally, the same units are used for both the energy content in feeds and the energy recommendations for the animals.

The energy recommendations used in Belgium, West Germany, the Netherlands, Sweden and United Kingdom are mainly estimated from metabolism trials, whereas those used in Denmark, Finland, France, Italy, Switzerland and Yugoslavia are mainly calculated from feeding trials.

\section{Energy content in feeds}

The energy content in the six different feeds is shown in Table 4. Within each country the variation in the energy content in the feeds is less for units of metabolisable energy than for units of net energy. This may be explained by a relatively higher energy content in forages - especially straw (Table 4a). In the French and the Dutch net energy systems forages have a relatively higher value for lactation than for maintenance + growth. In the Scandinavian feed unit system the factor for protein is high and leads to an overstimate of the energy content in concentrates whit a high protein content.

A more detailed comparison of the energy content of feeds, when various energy systems are used, was recently prepared by STEG and HoNING (1979).

\section{Energy content of feed rations - relative feeding level}

The total energy content in the five rations, for animals of 200 and $400 \mathrm{~kg}$ liveweight respectively, are shown in Table 5, and the corresponding levels of feeding on ration II through $\mathrm{V}$, relative to ration I, are in Table 5a.

Ration I has the highest energy content irrespective of the energy system used and in most cases ration II has the lowest energy content. For rations II and V (straw), to animals of $400 \mathrm{~kg}$ liveweight, the energy content was the same when calculated as SE, SFU and FFU. In most systems the energy content was higher for ration III (maize silage) than for ration IV (grass silage).

\section{Expected gain}

\section{Breeds :}

The representatives from France and Sweden completed table 3 for early, medium and late maturing breeds. The remaining representatives completed table 3 for medium maturing breeds only. References were made to the following medium maturing breeds :

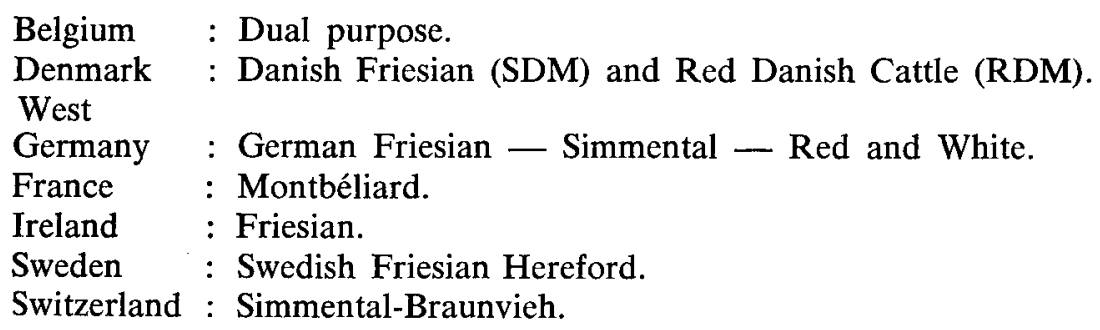




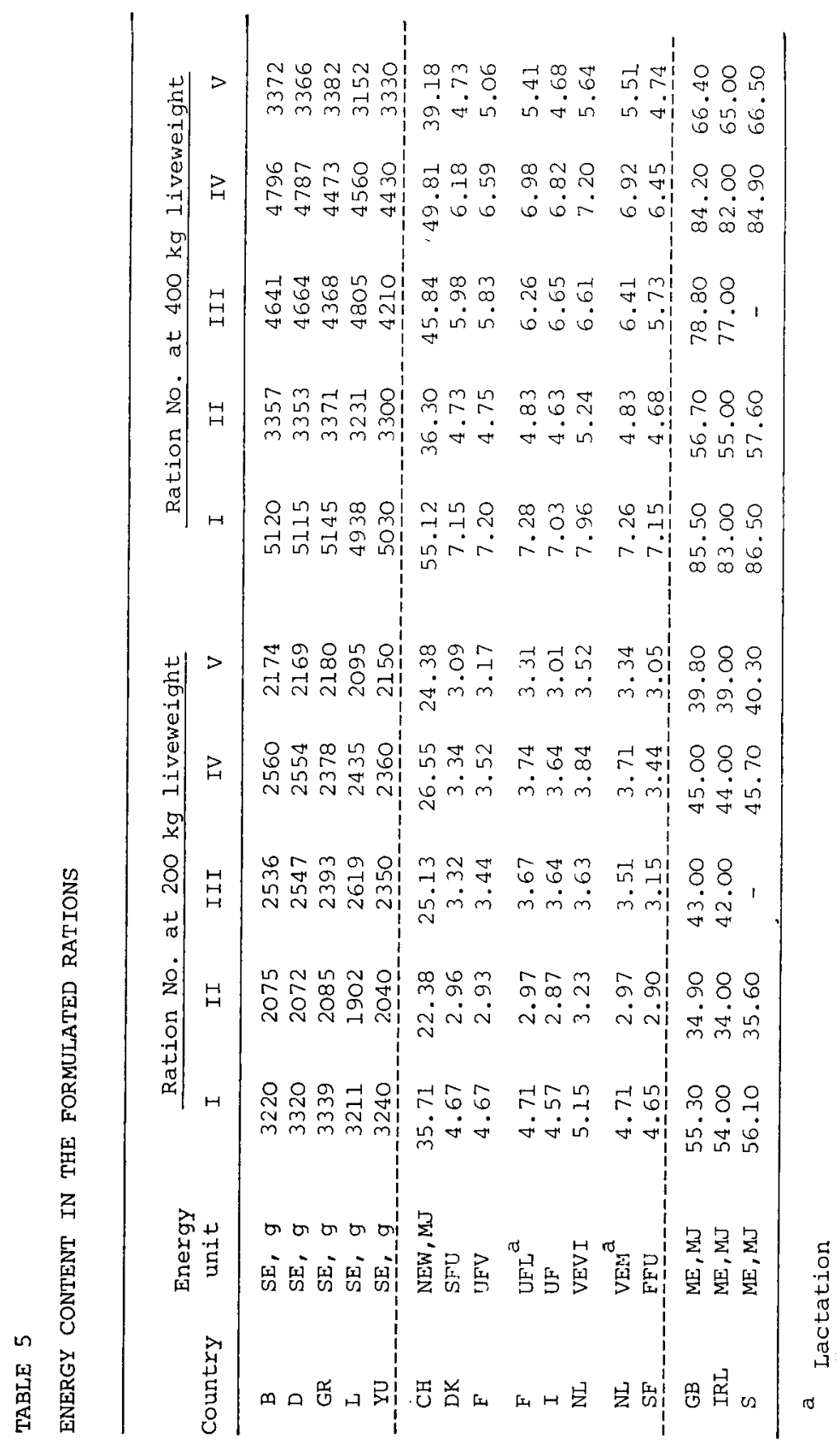




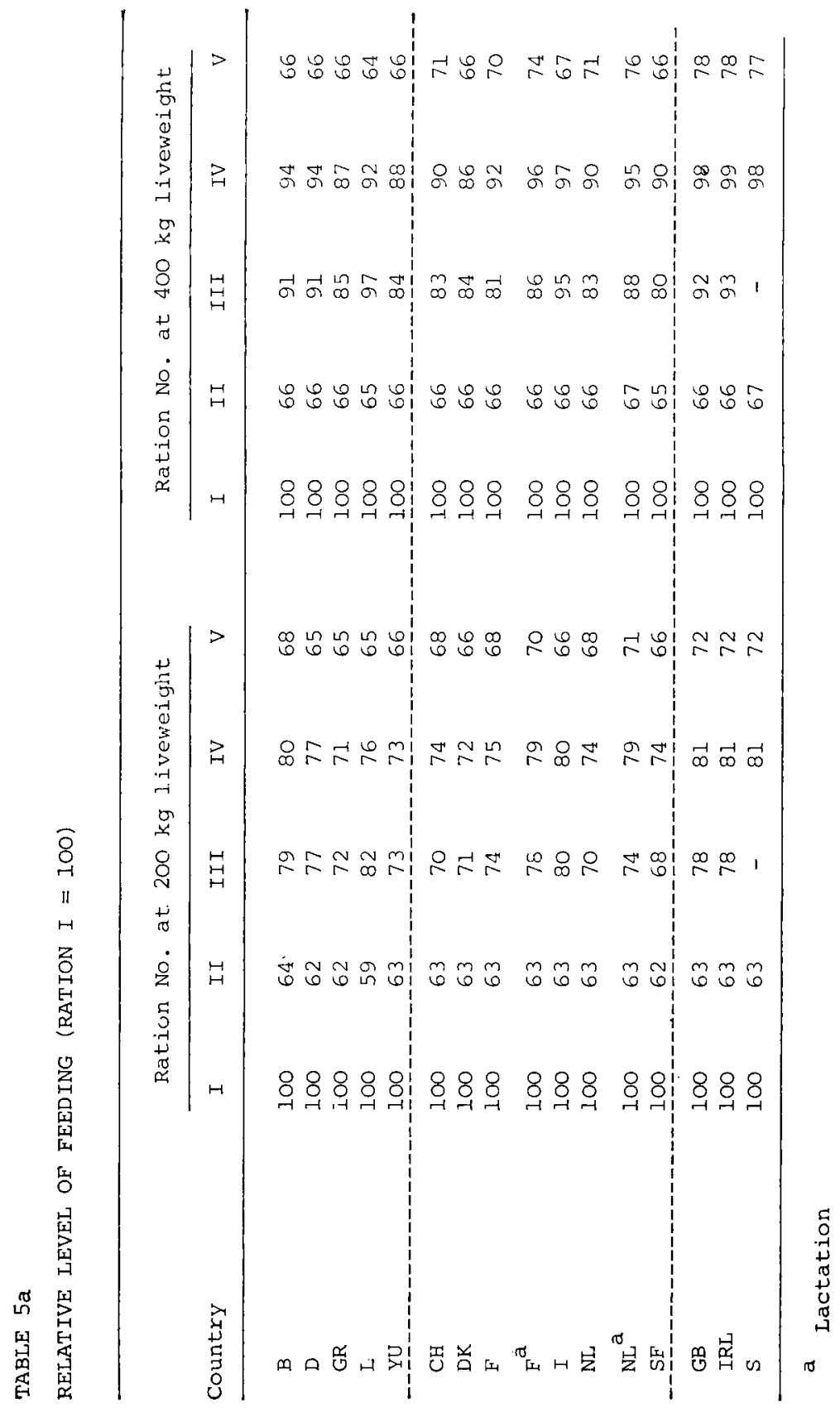




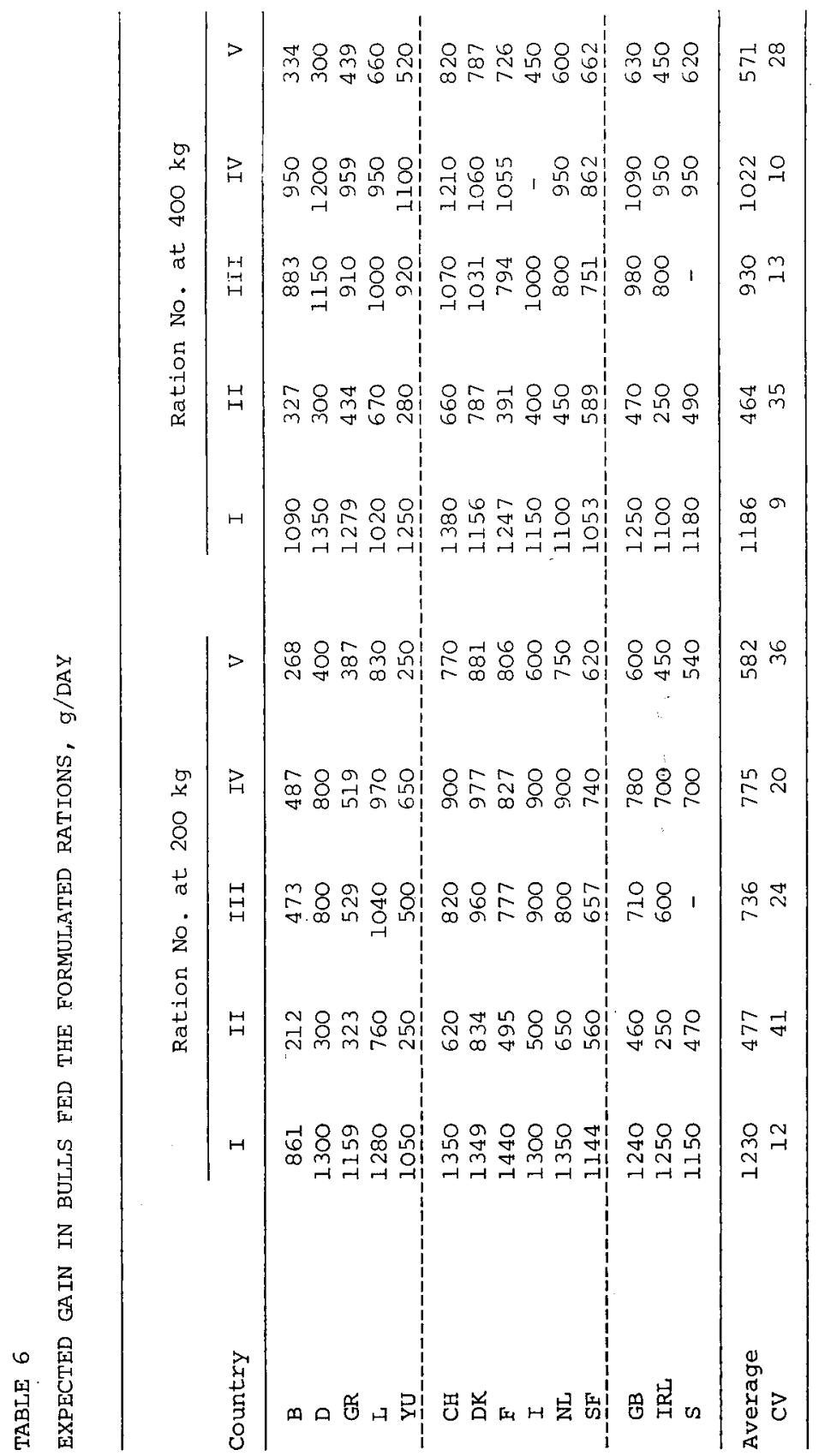




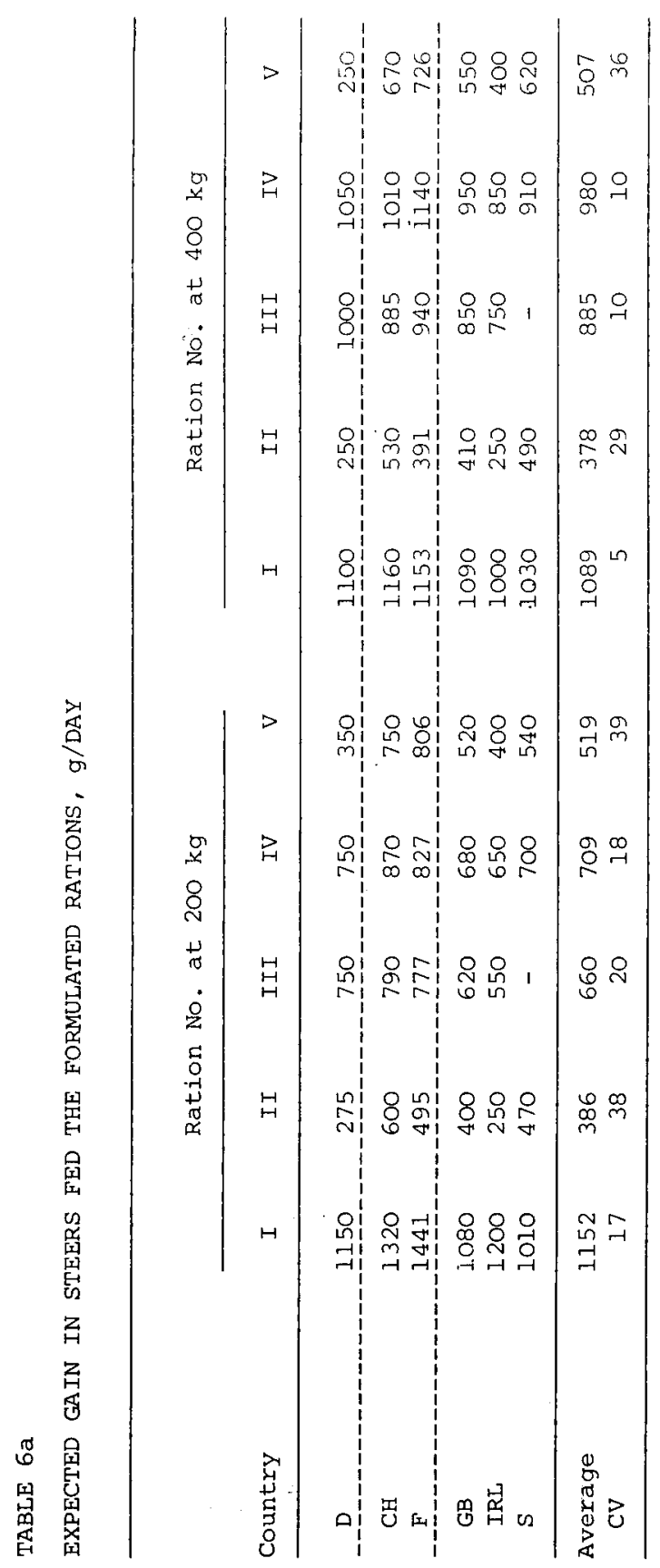




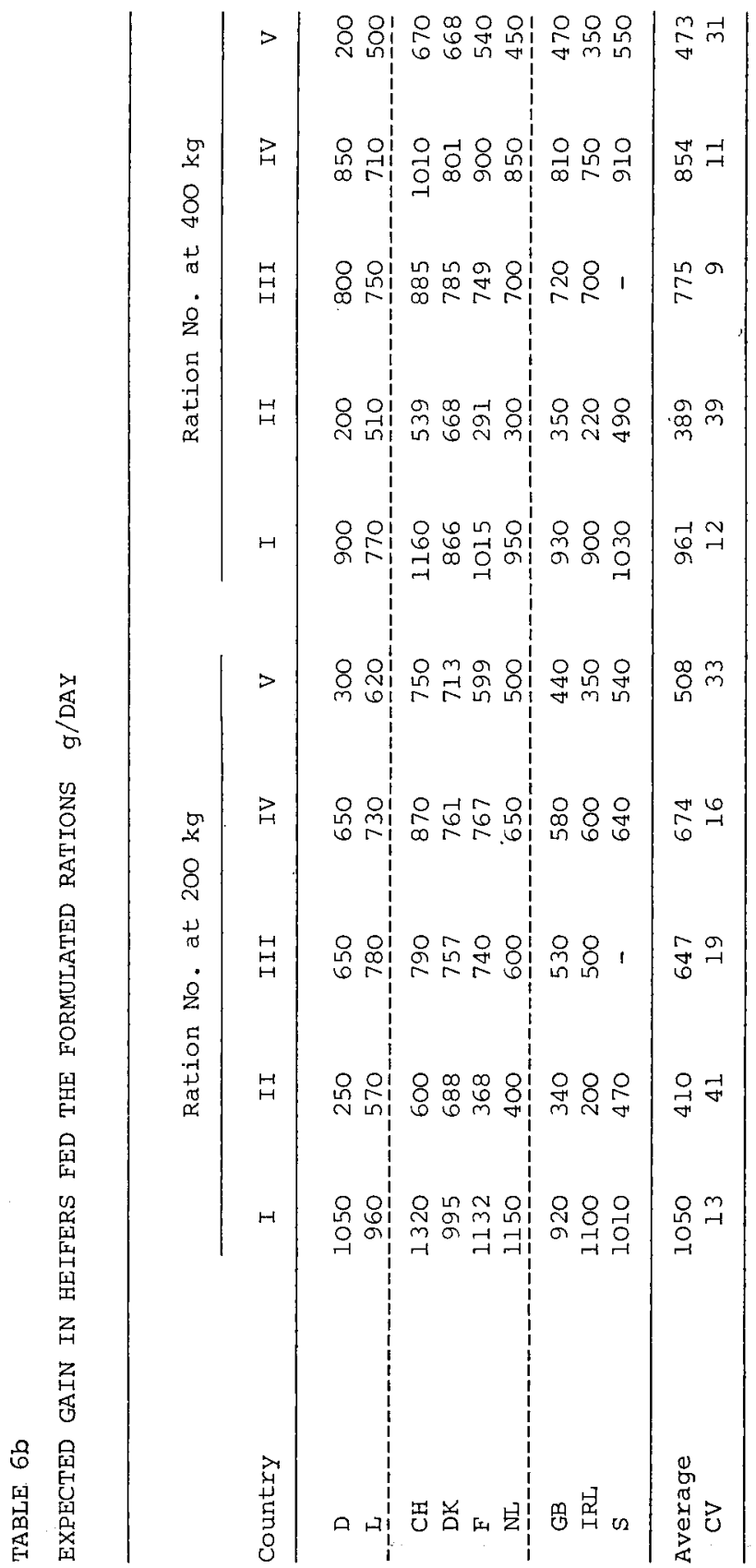



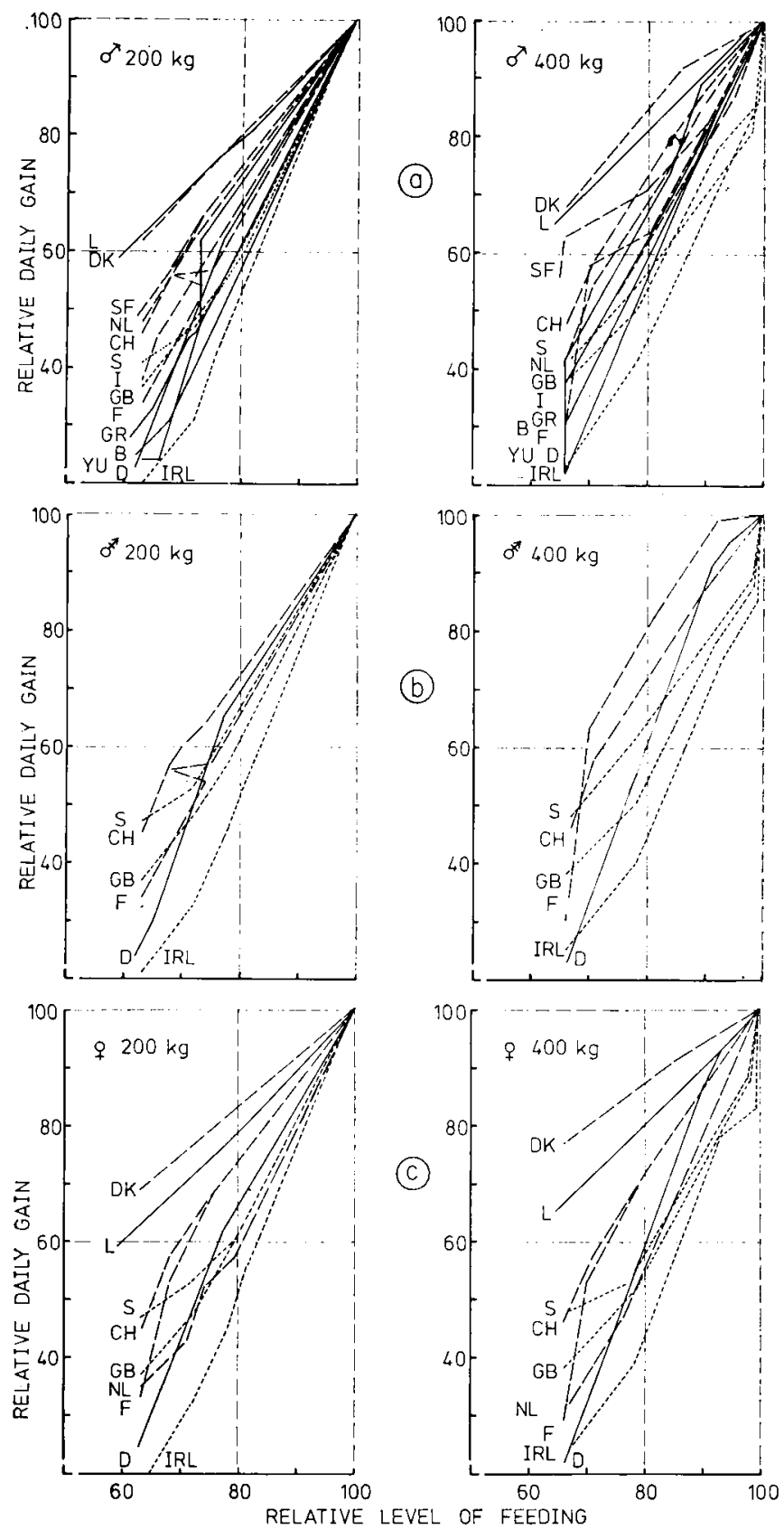

FIG. 1. - Relative daily gain at different levels of feeding.

a) Bulls at 200 and $400 \mathrm{~kg}$ liveweight respectively (Ration $I=100$ ).

b) Steers at 200 and $400 \mathrm{~kg}$ liveweight respectively (Ration $I=100$ ).

c) Heifers at 200 and $400 \mathrm{~kg}$ liveweight respectively (Ration $\mathrm{I}=100$ ). 
In France the Friesian is considered to be an early maturing breed.

The results do not allow comparisons of results for different maturing breeds. In the following all results are for medium maturing breeds, but differences between breeds cannot be excluded.

\section{Feed rations :}

The expected daily gain in bulls, steers and heifers fed the different rations are shown in Tables $6,6 \mathrm{a}$ and $6 \mathrm{~b}$ respectively. For ration $I$ the expected daily gains were approximately the same for all systems, but for the remaining rations the differences between systems were large-especially for rations II and V. The causes of the latter variations are in part due to differences in the relative energy content of the rations, but mainly due to large differences in expected gain in relation to the feeding level (energy standard). This is illustrated in figures 1 , $1 \mathrm{a}$ and $1 \mathrm{~b}$, for bulls, steers and heifers respectively. In these figures the relative daily gain (ration $I=100$ ) is plotted against the relative level of feeding. At low levels of feeding ( 65 per cent) the relative rate of gain varies from about 20 to more than 60 . This is equal to a three fold difference.

For Finland and the Netherlands, it was mentioned that expected gains of less than $700 \mathrm{~g}$ /day in bulls are unreliable. Furthermore, in the Dutch system daily gains in heifers in excess of $850 \mathrm{~g}$ are not well defined.

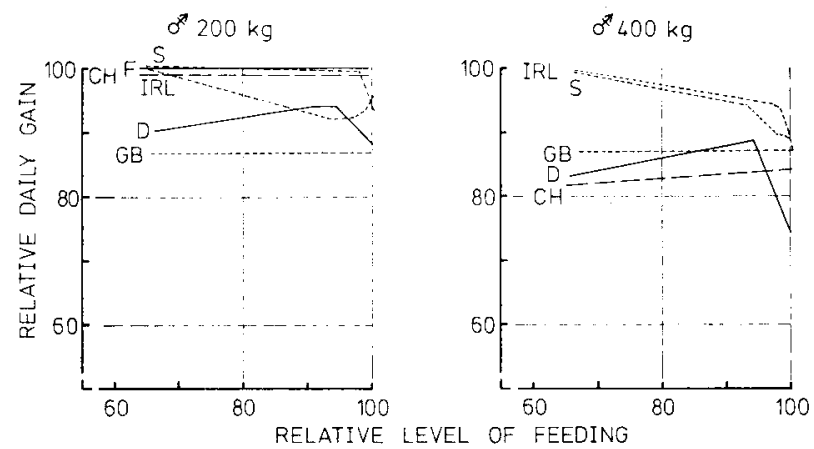

FIG. 2. - Daily gain in steers relative to bulls (100) at different levels of feeding.

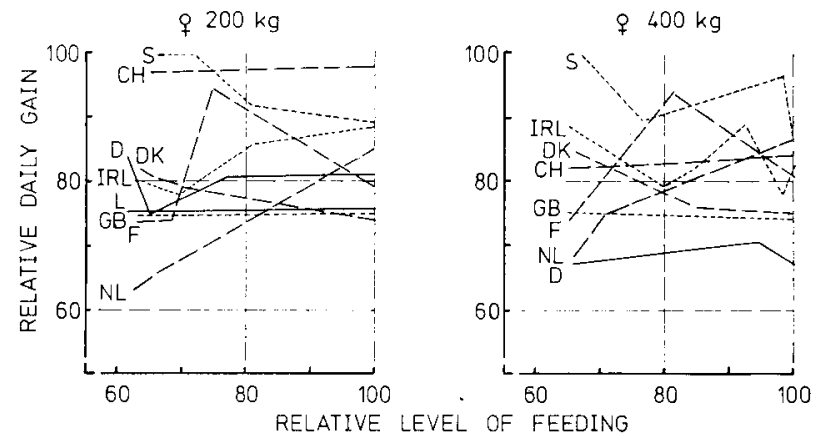

FIG. 2a. - Daily gain in heifers relative to bulls (100) at different levels of feeding. 
Difference between sexes :

The relative gain in steers in relation to bulls, and in heifers in relation to bulls, are illustrated in figures 2 and $2 \mathrm{a}$ respectively. In most countries the expected rate of growth in both steers and heifers are less than in bulls, but the differences vary from country to country. Whether the differences between sexes are decreasing or increasing at decreasing levels feeding, could not be clarified.
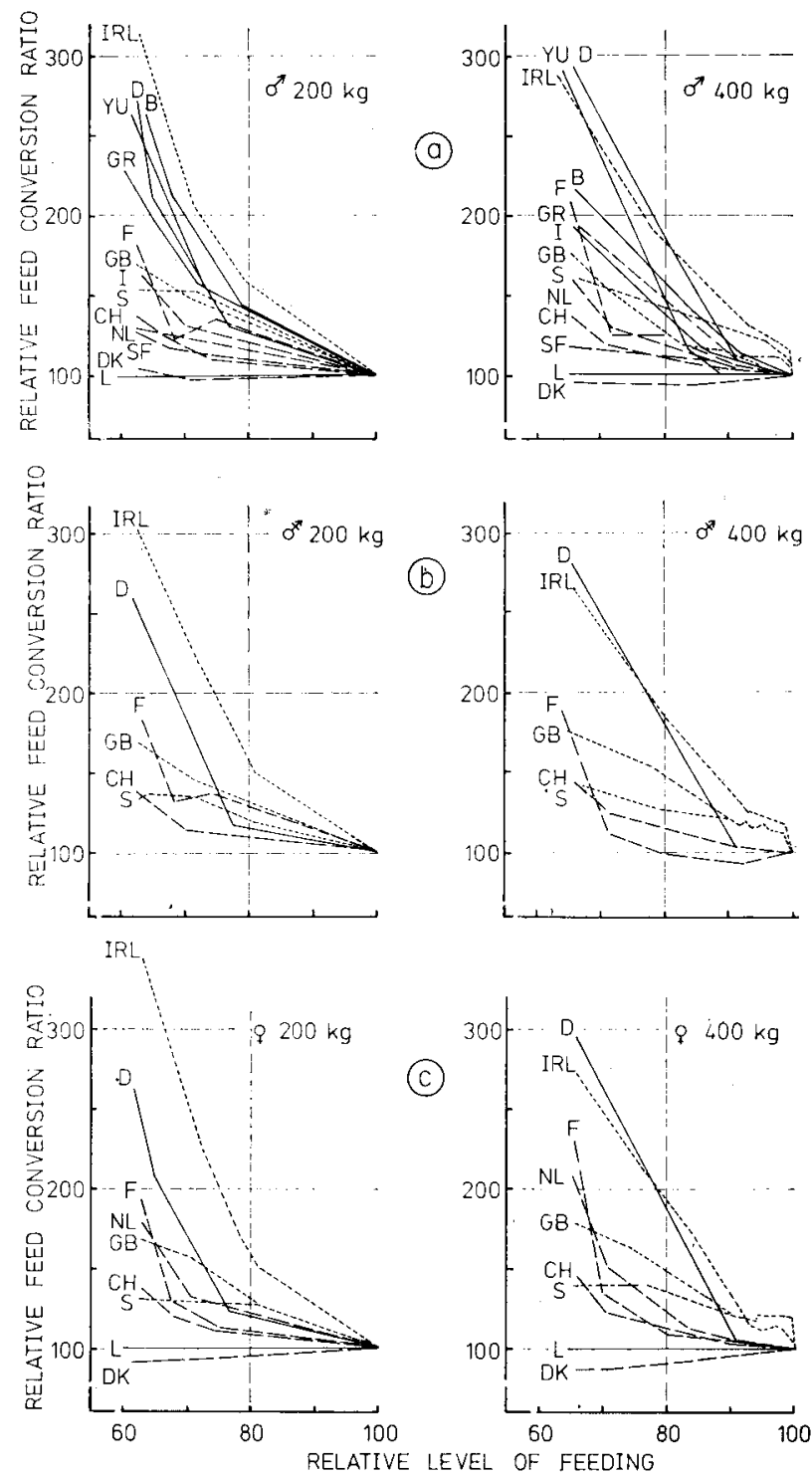

FIG. 3. - Relative feed conversion ratio at different levels of feeding.

a) Bulls at 200 and $400 \mathrm{~kg}$ liveweight respectively (Ration $I=100$ ).

b) Steers at 200 and $400 \mathrm{~kg}$ liveweight respectively (Ration $I=100$ ).

c) Heifers at 200 and $400 \mathrm{~kg}$ liveweight respectively (Ration $I=100$ ). 


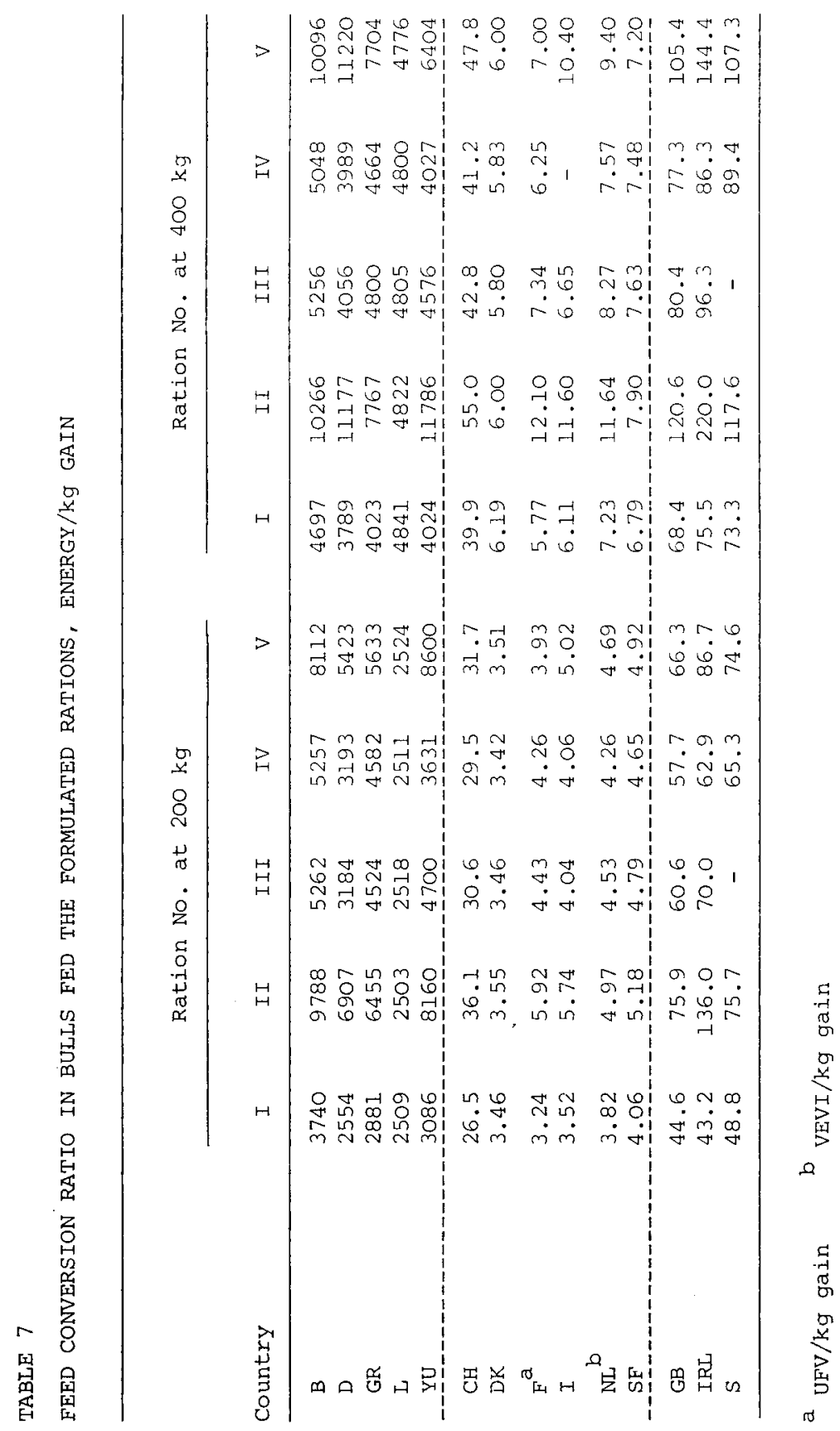




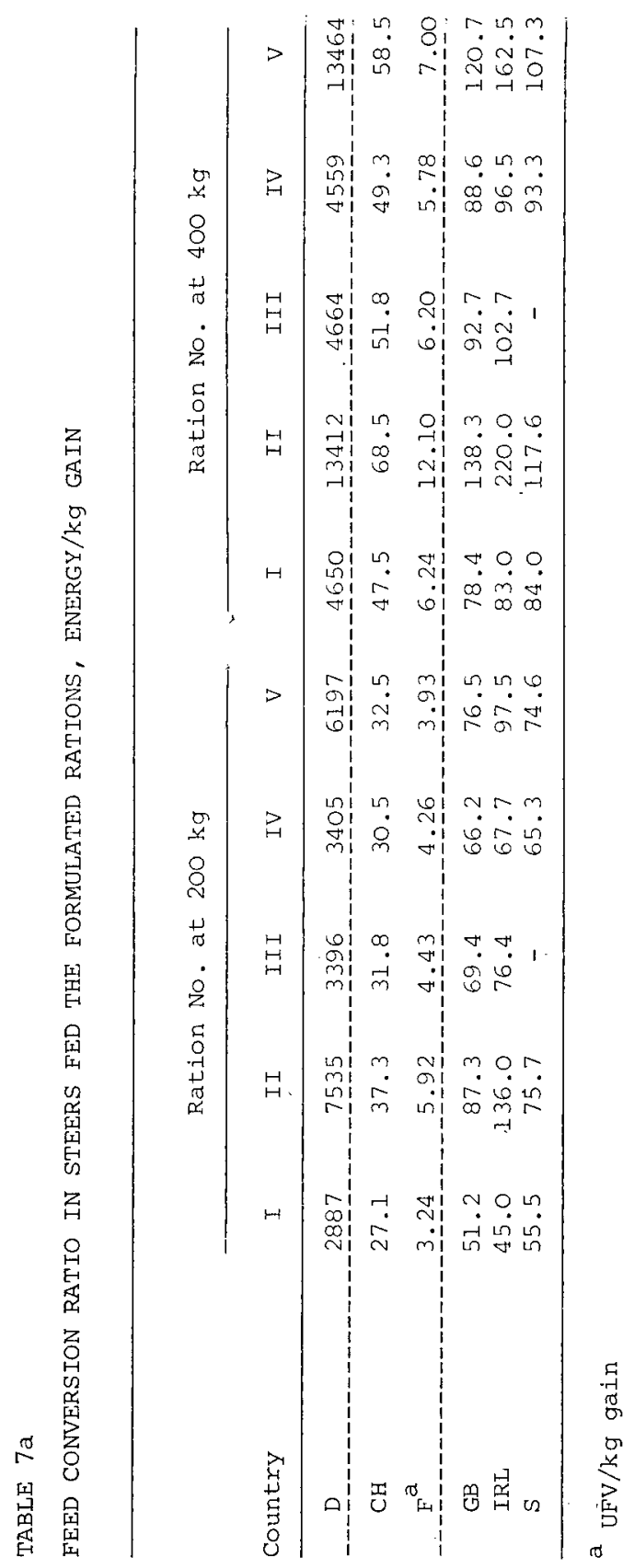




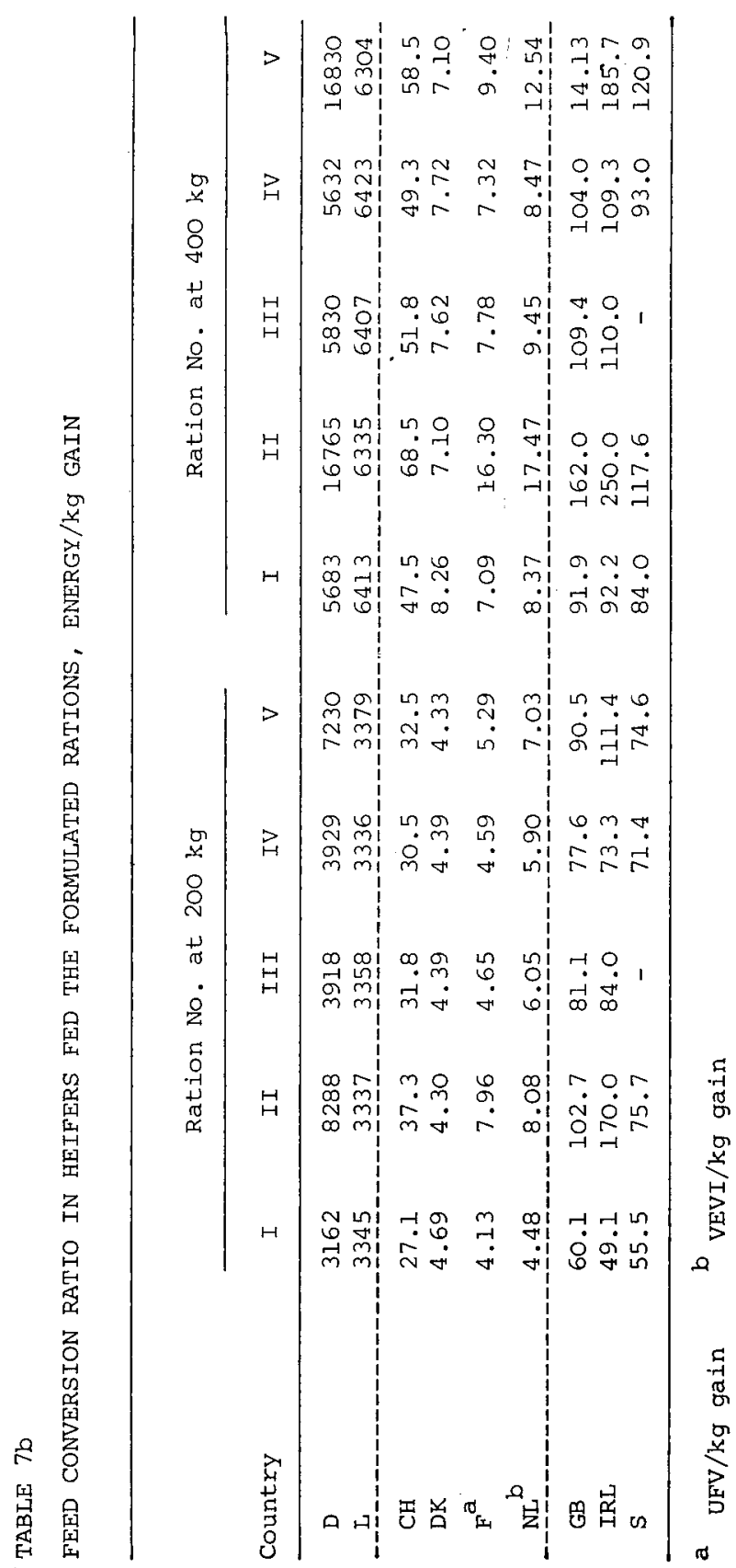


TABIE 8

RELATIVE FEED CONVERSION RATIO AT $400 \mathrm{~kg}$ LIVEWEIGHT IN BULLS, STEERS AND HEIFERS

\begin{tabular}{|c|c|c|c|c|c|c|c|c|}
\hline \multirow[b]{2}{*}{ Sex } & \multirow[b]{2}{*}{ Country } & \multicolumn{5}{|c|}{ Ration No. } & \multirow[b]{2}{*}{ Gns. } & \multirow[b]{2}{*}{$\mathrm{SD}$} \\
\hline & & I & II & III & IV & v & & \\
\hline \multirow{14}{*}{ Bulls } & $\mathrm{B}$ & 126 & 1.05 & 98 & 96 & 124 & 110 & 14.3 \\
\hline & $\mathrm{D}$ & 148 & 162 & 127 & 125 & 207 & 154 & 33.5 \\
\hline & $\mathrm{GR}$ & 140 & 120 & 106 & 102 & 1.37 & 121 & 17.4 \\
\hline & L & 193 & 193 & 191 & 191 & 189 & 191 & 1.7 \\
\hline & $\underline{\mathrm{YU}}$ & 130 & 144 & -97 & 111 & -74 & 111 & 27.5 \\
\hline & $\mathrm{CH}$ & 151 & 152 & 140 & 140 & 151 & 147 & 6.2 \\
\hline & DK & 179 & 169 & 168 & 170 & 171 & 171 & 4.4 \\
\hline & $\mathrm{F}$ & 178 & 204 & 166 & 147 & 178 & 175 & 20.8 \\
\hline & I & 174 & 202 & 165 & - & 207 & 187 & 20.6 \\
\hline & NL & 189 & 234 & 183 & 178 & 200 & 197 & 22.4 \\
\hline & _-_S $\mathrm{SE}_{-}$ & 167 & -153 & -159 & 161 & 146 & 157 & 8.0 \\
\hline & $G B$ & 153 & 159 & 133 & 134 & 159 & 148 & 13.1 \\
\hline & IRL & 175 & 162 & 138 & 137 & 167 & 156 & 17.3 \\
\hline & $\mathrm{S}$ & 150 & 155 & - & 137 & 144 & 147 & 7.8 \\
\hline \multirow{6}{*}{ Steers } & D & 161 & 178 & 137 & -134 & 217 & 165 & 34.0 \\
\hline & $\mathrm{CH}$ & 175 & 184 & 163 & 162 & 180 & 173 & 9.9 \\
\hline & $F_{-}$ & 193 & 204 & 143 & 136 & 178 & 171 & 30.1 \\
\hline & $\mathrm{GB}$ & 153 & 158 & 134 & 134 & 158 & 147 & 12.4 \\
\hline & IRL & 184 & 162 & 134 & 143 & 167 & 158 & 19.8 \\
\hline & $\mathrm{S}$ & 151 & 155 & - & 143 & 144 & 148 & 5.7 \\
\hline \multirow{9}{*}{ Heifers } & $D$ & 180 & 202 & 149 & 143 & 233 & 181 & 37.5 \\
\hline & $=-$ & 192 & 190 & 191 & 193 & 187 & 191 & -2.3 \\
\hline & $\mathrm{CH}$ & 175 & 184 & 163 & 162 & 180 & 173 & 9.9 \\
\hline & DK & 176 & 165 & 174 & 176 & 164 & 171 & 6.0 \\
\hline & $\mathrm{F}$ & 172 & 205 & 167 & 159 & 178 & 176 & 17.5 \\
\hline & NL & 187 & 216 & 156 & 144 & 178 & 176 & 28.1 \\
\hline & GB & 153 & 158 & 1.35 & 134 & 156 & 147 & 11.7 \\
\hline & IRL & 108 & 147 & 131 & 149 & 167 & 156 & 21.8 \\
\hline & $\mathrm{s}$ & 151 & 155 & - & 130 & 162 & 1.50 & 13.8 \\
\hline
\end{tabular}

(feed conversion ratio at $200 \mathrm{~kg}=100$ )

\section{Feed conversion ratio}

According to numerous feeding trials conducted in various countries, the feed conversion ratio (energy intake $/ \mathrm{kg}$ gain) increases with the level of feeding (ANDERSEN, 1977). Whether this is considered in formulating the energy standards was also investigated. The feed conversion ratio was calculated for each ration (Tables $7,7 \mathrm{a}, 7 \mathrm{~b}$ ), and the relative feed conversion ratio was then plotted against the relative level of feeding (figures $3,3 \mathrm{a}, 3 \mathrm{~b}$ ). The results are variable, 
but in most countries the feed conversion ratio decreases at increasing levels of feeding. These results are in contrast to the existing evidence mentioned above. It is well known that the energy intake per $\mathrm{kg}$ gain is larger at 400 than $200 \mathrm{~kg}$ liveweight. The relative increases are shown in table 8 , and they vary from country to country.

\section{References}

ANDERSEN H.R., 1978. Effect of energy level on growth and efficiency. In H. De Boer, and J. Martin, eds. Patterns of growth and development in cattle. A seminar in the EEC programme of co-ordination of research of beef production, held at Ghent, October, 1977.

Steg A., VAN Der Honing Y., 1979. Relationships between energy values predicted with several feed evaluation systems for dairy cows. Doc. Report No. 49 IVVO, Lelystad. 


\section{Discussion}

\section{Chair : R. JARRIGE (France)}

A.J.H. VAN Es (The Netherlands). - I have just a comment on Professor NeimannSørensen's remarks regarding APL (animal production level) and the correction for the feeding level with regard to digestibility. In fact, APL is being used after you have obtained metabolisable energy at the feeding level used. So first there is a correction of feeding level on metabolisable energy, and then you start with the metabolisable energy being used for maintenance and for fattening. This is where APL comes in. In the case of beef cattle, we have argued that the feeding level with regard to digestibility depression, is usually low. For that reason we have not included any correction in the Dutch system; it is the same with the Swiss system.

A. NeIMANN-S $\phi$ RENSEN (Denmark). $-\mathrm{I}$ did point out that there was a difference with the French system. However, you still have these corrections. When you make the norms you have +10 per cent according to weight, and from -2 to +8 , according to growth rate. These are some adjustments based on feeding experiments.

A.J.H. VAN Es. - That is, of course, at the end - I agree with you completely that starting with a theoretical model, which is our first approach, and then finally coming to the practical situation in combination with the theory, you have to include results from feeding trials because our theoretical data are not precise enough at the moment.

\section{A. Neimann-S $\phi$ RENSEN. - Yes, but you still prefer the factorial method ?}

A.J.H. VAN Es. - I think that it is more sound, physiologically; it gives a better approach to what is really happening. Many processes are going on at the same time and you can work them out separately.

H. Bickel (Switzerland). - I would like just to comment on Professor NeimannSørensen's table 2, with respect to Switzerland. With regard to the estimation of energy standards for beef cattle, it is true that they came from feeding experiments but we re-calculated the energy intake with feed values expressed as net energy gain. Then we deducted the maintenance requirement, the same as Dr. Van Es is using, which gives us the net energy of gain which we can compute together with the daily weight gain and the weight of the animal. We always take into account a correction for APL. So, in fact, all variations in maintenance requirement due to feeding level, breed or sex, are included in the energy concentration of the daily gain. It is a combination of the factorial approach and the results of the feeding experiments.

A. Neimann-Sørensen. - So my table is not quite correct, but it was not clear to me exactly what was done from the information I received. Now we have some more information. If we can improve on this table, so much the better.

G. Alderman. (UK). -

ANIMAL PRODUCTION LEVELS FOR CATTLE

\begin{tabular}{ccccc}
$\begin{array}{c}\text { Liveweight } \\
(\mathrm{kg})\end{array}$ & 0 & 0.5 & 1.0 & 1.5 \\
\hline & 1.00 & 1.33 & 1.79 & - \\
200 & 1.00 & 1.29 & 1.70 & 2.33 \\
300 & 1.00 & 1.26 & 1.64 & 2.22 \\
400 & &
\end{tabular}

Based on APL $=\frac{E_{m}+E g}{E_{m}}$ 
These figures are merely descriptive of the APL situation. In the UK situation we compute metabolisable energy to its appropriate net energy in a continuous function. There are no steps in the situation. If you decide to use an APL of 1.5 to calculate your net energy for intensive beef production, then the rations that have been issued for us to calculate do not fall neatly on to that column. Where the mean liveweight gain is $400 \mathrm{~g}$, with a variation from about 200 up to $600 \mathrm{~g}$, it is obviously well below the value of 1.5 , and this would explain some of the variations. You are using a net energy for maintenance and growth which is not appropriate to low levels of feed intake.

That is what the Harkins function for APL tells you. You will see that for ration I which has a mean gain of $1.2 \mathrm{~kg}$, or $1200 \mathrm{~g}$, there is an APL of about $1.8-1.9$, so an APL of 1.5 is not correct for this either.

Our colleagues in France, Holland and Switzerland, are using a very similar mathematical function for calculating the joint efficiencies for maintenance and growth.

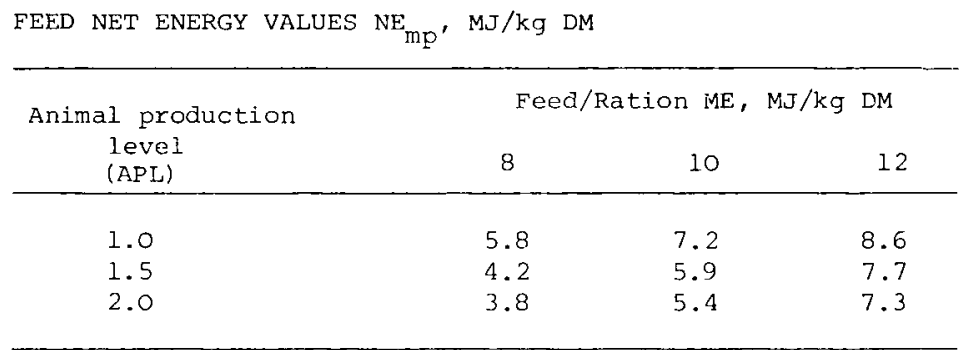

The net energies that you will compute in $\mathrm{MJ} / \mathrm{kg} \mathrm{DM}$ depend on the metabolisable energy and there will be very large differences depending either on ME or on the APL. So, it is important to recognise that the decision to choose an APL of 1.5 introduces systematic errors if you are substantially away from the assumed mean, or average, liveweight gain.

I just wanted to demonstrate that and to make the point very firmly that the UK system is a continuous function and is not liable to such errors.

A.J.H. VAN Es. - In the Dutch system we are well aware of this problem and we have included a correction for it. If the APL is not 1.5 a correction is added to the feeding standards, to the requirements. So in the long run it does not show up in the feed values but it does show up in the feeding standards - I don't think we make an error here.

G. Alderman. - Would our Dutch colleagues care to indicate which decision they took for the five rations. Did you use the UFL, VEM or VEVI ?

A.J.H. VAN Es. - We gave both. For the rapidly growing bull, we used the beef value and for the heifer which will become a dairy cow, we used the lactation unit because we do not like to work with two kinds of feeding values for milking cows and heifers on the same farm.

G. Alderman. - Yes, but you have put the correction into the animal requirements and not into the net energy of the feed.

H. BickeL. - Yes, certainly. And there is no difficulty at all in making the necessary calculations.

G. Alderman. - I think the point that needs to be made is that this means that your net energies for growth are not now true net energies, they are corrected.

H. BICKEL. - They are true net energies for the APL 1.5; after that they can all be related to the APL 1.5. They are not true net energies, that is correct, in terms of the energy balance. If the APL is higher then the true net energy is lower; if the APL is lower, the true net energy will be higher. 
M. Vermorel (France). - In the French system we expressed the net energy value of feedstuffs in feed units which are related to the energy value of barley. This means that if there is a difference in the APL between the value we have chosen of 1.5 and the true APL of the animals, there is an error in the net energy value of the feed and also in the net energy value of barley. So the relative error is smaller than the absolute value error.

The other point I would like to mention is that according to the data obtained by Robelin, Geay, and their colleagues on the composition of body gain of growing cattle, it seems that the APL ranges from 1.4 to 1.6 or 1.7 for weight gains ranging from 1.0 to 1.4 or $1.5 \mathrm{~kg} /$ day, at least for French breeds.

These two aspects mean that the errors are not so important for practical purposes.

G. Alderman. - That is an important point because APL, as Harkins defined it, is the ratio between the energy retained and the energy for maintenance. If you have bulls with low energy values in gains, then the APL will be different from the values that we have put up. Our APL values are only true for our function for the net energy of gains and they are appreciably higher than those for bulls fed intensively as in France.

Y. GFaY (France). - Dr. Refsgaard Andersen, you were surprised by the fact that the feed efficiency decreased when you compared the different diets. I do not find it surprising bearing in mind the range of daily gain. For example, for the medium maturing bulls, the daily gain decreased from $1.4 \mathrm{~kg}$ to 0.7 or $0.8 \mathrm{~kg}$. We have shown that the feed efficiency moves purely linearly with feed intake. The feed efficiency increases or decreases according to which part of the curve you consider. It depends on the proportion of energy for gain in relation to the total energy requirement of the animal.

H. Refsgaard Andersen (Denmark). - Yes, I think I agree with you but it will be discussed later on. I have not tried to say which system is best; I have only tried to indicate what the different systems show.

J. Robelin (France). - I would like just to go back to the discussion on APL and the determination of net requirement of energy for growth. As far as growing cattle are concerned, we have calculated the net requirement for growth with feeding trials, as has been said. We know that there is a continuous increase in APL with body weight gain. However, when we use feeding trials to estimate the requirement for growing cattle, if there is a bias in the estimation of the value of feedstuffs, it is removed by the estimation of net requirement from feeding trials. This is one of the reasons why we prefer feeding trials to factorial methods.

Secondly, I have a comment on what was said by Dr Van Es on factorial methods. Certainly it is more satisfactory to use factorial methods to analyse what is happening during growth, step by step. However, the problem is to find a good factorial model. For example, the most commonly used model is maintenance + growth which is sometimes divided into protein and lipid growth, so you can calculate metabolisable energy intake, but the model is not always sufficiently good to give accurate results.

A.J.H. VAN Es. - I don't think the situation is as bad as one might suppose from the variations in Dr. Refsgaard Andersen's paper. For instance, we like to grow bulls at rapid rate of gain so we are not usually interested in a gain of $0.5 \mathrm{~kg}$ but rather in a daily gain of $1 \mathrm{~kg}$ or more. With regard to the heifers, we are not interested in very high rates of gain, we are interested in a daily gain of, perhaps, $0.6 \mathrm{~kg}$. If you look at all the requirements and standards given, you will find results for bulls and heifers not so very far removed from these levels.

H. ReFsgaARD ANDERSEN. - I agree that the figures in my paper show bigger differences than you find in practice - I was aware of this when $I$ formulated the questionnaire because I think it is interesting to see what happens over a wide range. But we have to know what happens with feed efficiency at different daily gains when we make an economic evaluation of various rations.

A. Neimann-Sørensen. - May I ask Mr. Alderman, how does your system work in England? In my country we like our farmers to use and understand the system.

G. Alderman. - Yes indeed, it is a matter, as aiways, of relative errors. The implication that, in practice, farmers are least-costing their rations or seeking optimum feed efficiencies, 
is not the reality of advice to farmers who are raising livestock for replacements to their dairy herds, and so on.

They set a target for animals to gain at a certain rate, to be sold, or to be put to the bull, by a given date and ask for a ration which will achieve the required performance. That is the main requirement we have from our farmers. In that context, they are very happy, primarily because they do not work the rations out. The situation in the UK is that only 3 per cent of the population is in agriculture and there is a large support industry - feed manufacturers, Milk Marketing Board, Ministry of Agriculture, etc. So anyone who wants to have rations calculated for him has only to lift up a telephone and ask. He will get it done free by professional nutritionists. So the three table problem is no problem to a nutritionist; the ration formulation can be done very rapidly, we can linear programme smoothly if we have decided what the frame of reference is. If the animals weigh $400 \mathrm{~kg}$ and are required to gain at $0.7 \mathrm{~kg}$; you calculate the appropriate net energies, put them into your least-cost ration formulation and it runs very nicely, it will optimise - but there is not that much of a demand.

The other point I thought it would be interesting to comment on is what is the experience in practice. I would just like to remind you of the original work that we did $\left(^{*}\right)$ because $I$ think it puts in context the question of low rates of gain and the big variation in results demonstrated by Dr. Andersen and the fact that a number of us have used feeding trials to adjust the requirements to be correct. I think you will find that the French, the Swiss and the Dutch results are all in the centre of Dr. Andersen's figure.

Y. GeAY. - Since I have to present the nitrogen standard in a few minutes I would like to point out that if we take the nitrogen level of the different diets into account it is likely that our bulls will not achieve the level of daily gain that energy intake has permitted. Some of the discrepancies which have been observed between diets may certainly be due to the differences in nitrogen level.

\section{G. Alderman. - Yes indeed. It is a point we need to watch and bring out later.}

R. JARRIGE. - The discrepancies between the different systems can be considered as large or small ; it depends on your philosophy. The differences arise from different points. The first point is that there are some differences in the nutritive value of the feeds ; probably we can minimise the discrepancies there, especially between people using net energy systems in terms of feed units. Secondly, discrepancies are found in the standards. There are probably some differences related to the breeds and to the systems of production. In our country, we have a lot of breeds, a lot of systems of production, and we have the three species : cattle, including suckling cows, sheep and goats. So, when we prepare our new systems we have to take into account the fact that we have a wide range of animals. The differences between breeds could be important when we are considering slow growing animals because the proportion of maintenance is much higher than with fast growing animals or with high yielding dairy cows. If we consider the different standards for high yielding dairy cows, the differences are very low.

The third cause of the discrepancies is probably the scientific knowledge or the feeding experiments available. Certainly the number of feeding trials appears more important for fattening animals than for animals growing at a low rate.

Finally, there are historic and philosophical differences. They have been apparent in the discussion between Mr. Alderman and Professor Neimann-Sorensen. As in Denmark, we are thinking more in terms of the farmer's requirements and we want to prepare diets for animals with a fixed level of production whereas others have the philosophy of predicting liveweight gains from the diet availabie. This certainly explains some discrepancies.

$\left({ }^{*}\right)$ See Table 3.1 of Proc. 7th Nutrition Conférence foor Feed Manufacturers pages, 37-38, 1973. Butterwprths. 